
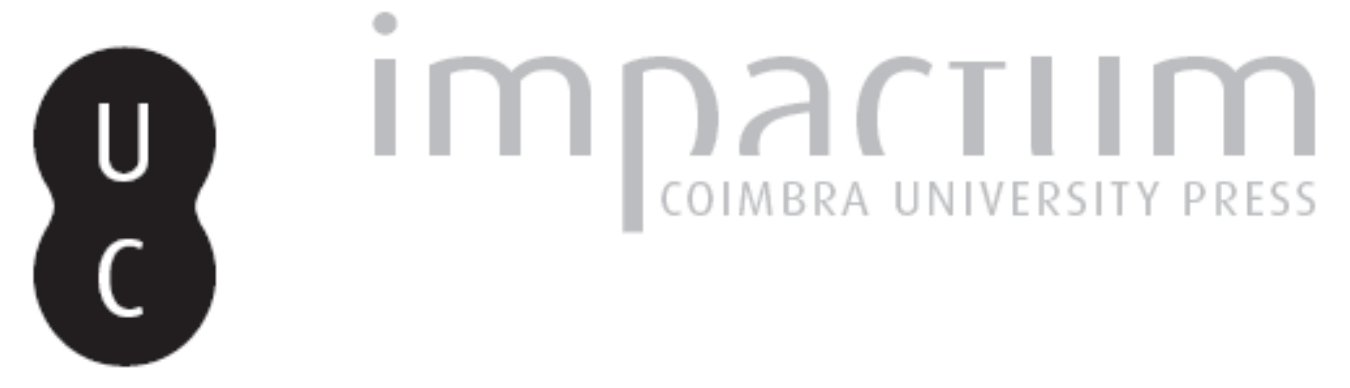

Regiões ultraperiféricas (Açores e Madeira): mais-valia de Portugal na Europa

Autor(es): $\quad$ Silva, Guilherme

Publicado por: Centro de Informação Europe Direct de Aveiro; Centro de Estudos

Interdisciplinares do Século XX

URL

persistente:

URI:http://hdl.handle.net/10316.2/37111

DOI:

DOI:http://dx.doi.org/10.14195/1647-6336_12_6

Accessed : $\quad$ 26-Apr-2023 16:09:38

A navegação consulta e descarregamento dos títulos inseridos nas Bibliotecas Digitais UC Digitalis, UC Pombalina e UC Impactum, pressupõem a aceitação plena e sem reservas dos Termos e Condições de Uso destas Bibliotecas Digitais, disponíveis em https://digitalis.uc.pt/pt-pt/termos.

Conforme exposto nos referidos Termos e Condições de Uso, o descarregamento de títulos de acesso restrito requer uma licença válida de autorização devendo o utilizador aceder ao(s) documento(s) a partir de um endereço de IP da instituição detentora da supramencionada licença.

Ao utilizador é apenas permitido o descarregamento para uso pessoal, pelo que o emprego do(s) título(s) descarregado(s) para outro fim, designadamente comercial, carece de autorização do respetivo autor ou editor da obra.

Na medida em que todas as obras da UC Digitalis se encontram protegidas pelo Código do Direito de Autor e Direitos Conexos e demais legislação aplicável, toda a cópia, parcial ou total, deste documento, nos casos em que é legalmente admitida, deverá conter ou fazer-se acompanhar por este aviso.

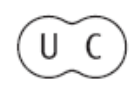


DEBATER

A EUROPA

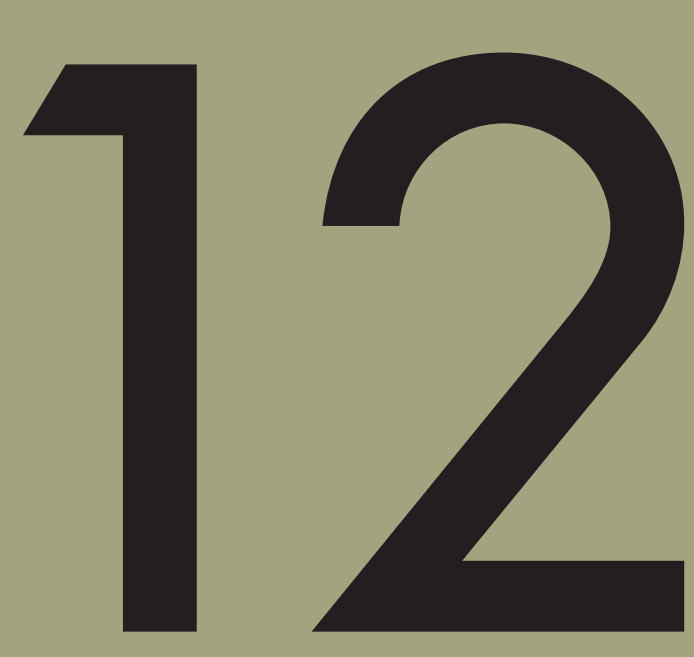

jan-jun 2015

POLITICAS REGIONAIS DA UE

EU REGIONAL POLICIES 


\title{
Regiões Ultraperiféricas (Açores e Madeira) Mais-valia de Portugal na Europa
}

\author{
Guilherme Silva \\ Deputado à Assembleia da República \\ Vice-Presidente da Assembleia da República \\ E-mail: gp_psd@psd.parlamento.pt
}

\begin{abstract}
Resumo
Nesta comunicação o autor dá a conhecer as Regiões Ultraperiféricas (Madeira e Açores) como uma mais-valia de Portugal na Europa.
\end{abstract}

Palavras-chave: Regiões Ultraperiféricas; Europa; Portugal; Madeira, Açores

\begin{abstract}
In this paper the author unveils the outermost regions (Madeira e Açores) as added value of Portugal in Europe.
\end{abstract}

Keywords: Outermost regions; Europe; Portugal; Madeira, Azores

A escolha que fiz do tema que me proponho abordar, resultou de um impulso de ocasião, ainda que, porventura, não tão repentista quanto a forma como estou a colocar a questão possa aparentar ${ }^{1}$.

\footnotetext{
${ }^{1}$ Este texto resulta da comunicação oral proferida pelo Dr. Guilherme Silva, Deputado à Assembleia da República, apresentada no Ciclo de Conferências $O$ (Re)encontro da Tradição Atlântica que teve lugar na Universidade de Coimbra, no dia 5 de Março de 205. Confesso que não ponderei o peso e a especial responsabilidade de uma intervenção no âmbito da $17^{\text {a }}$ Semana Cultural da Universidade de Coimbra, integrada nas Comemorações dos seus 725 anos - "Tempo de Encontros - O Reencontro com a Tradição Atlântica”. Para quem como eu, teve, no passado, uma relação próxima com esta Universidade e dela recolheu ensinamentos sempre presentes, e indissociáveis, do melhor do seu percurso de vida, dificilmente poderia dizer que não ao honroso pedido da Senhora Vice-Reitora Clara Almeida Santos. Acresce que, no caso, este não era apenas um "Encontro", mas, antes, um "Reencontro", o "Reencontro com a Tradição Atlântica", tema de especial interesse para um madeirense que se vem batendo, de há muito, pela valorização da vertente Atlântica de Portugal, com particular envolvência das suas Regiões Autónomas insulares. Não posso deixar de registar a total liberdade que me foi dada para escolher a vertente, ou subtema que pretendesse aqui abordar. Infelizmente, acontece sempre o mesmo (pelo menos a mim!), quando recebo, como foi o caso, com bastante e amável antecedência, o convite para intervir em
} 
$\mathrm{Na}$ verdade, penso que tal impulso terá decorrido de um duplo incómodo acumulado, nas duas últimas décadas, de, por um lado, Portugal, na Europa, ser visto mais como um beneficiário de ajudas europeias (situação acentuada com o Programa de Ajustamento Financeiro a que estivemos sujeitos nos últimos anos), do que propriamente um País que seja, ou traga, uma mais-valia para a União Europeia.

Por outro lado, as Regiões Autónomas são igualmente encaradas, nessa mesma óptica de regiões carenciadas, também elas dependentes de Programas e de Apoios próprios para as chamadas Regiões Ultraperiféricas.

E, no plano interno, infelizmente, tem-se exacerbado essa mesma ideia, das Regiões Autónomas, em especial a Madeira, como sorvedouros financeiros do Estado. Admito, pois, que a escolha do tema, ou os termos como o formulei, talvez tenham sido uma reacção ao cansaço a um juízo sobre Portugal, no contexto da União Europeia, que não me parece nem justo, nem rigoroso.

Como não é, igualmente, justo, nem rigoroso, quer o juízo interno, quer o sentimento europeu, relativamente às nossas Regiões Autónomas. Em todo o caso, se fizesse agora, neste momento, a escolha do tema "Regiões Ultraperiféricas (Açores e Madeira): Mais-valia de Portugal na Europa”, talvez lhe acrescentasse, prudentemente, uma interrogação.

Partiria, assim, de um patamar menos afirmativo e procuraria, por via da própria intervenção, afastar, tanto quanto possível, a forma interrogativa.

Os tempos, infelizmente, são de prevalência do económico, do financeiro e do orçamental sobre tudo o mais, e, portanto, não espanta a óptica com que, dominantemente, se avalia a presença de Portugal na União Europeia, incluindo nessa avaliação as Regiões Autónomas insulares.

É sabido que Portugal, ao integrar a então Comunidade Económica Europeia (hoje União Europeia), o fez de corpo inteiro, levando consigo, sem reservas (salvo uma

Colóquios ou Conferências. Parece que vamos ter todo o tempo do Mundo para fazer algo de cuidado e de mais profundo, como se exigia. Depois, vamos sendo absorvidos pelos sucessivos "imediatos", que se nos apresentam, e damos por nós, nas vésperas, a improvisar e a tentar compor o melhor possível. E foi isso que, mais uma vez, aconteceu, do que me penitencio perante todos vós e em especial face aos responsáveis pela organização deste Ciclo de Conferências, que tiveram a amabilidade de me convidar e me concederam a honra de aqui estar. Achei, antes de mais, interessante e curioso que, tendo cada um de nós feito individualmente, ao que penso, a escolha da vertente a abordar, se pressinta no seu enunciado, a afinidade, se não mesmo, em alguns casos, a eventual coincidência parcial dos temas. Refiro-o, não como observação crítica, que, aliás, não teria qualquer sentido, mas, bem pelo contrário, por me parecer mesmo enriquecedor, o registo de ópticas e abordagens múltiplas de matérias tão relevantes, como as que aqui hoje tratamos, graças a esta feliz iniciativa da Universidade de Coimbra. 
mera declaração sobre as suas especificidades), a Região Autónoma dos Açores e a Região Autónoma da Madeira

Isto significa que Portugal, o Estado Nação mais antigo da Europa, levou consigo, tanto a sua História como a sua Geografia.

Ora, nessa História está a circunstância de ter levado o espírito da Europa, universalizando-o, por via da epopeia dos Descobrimentos, aos quatro cantos do Mundo, ou seja, a terras e gentes de antes desconhecidas.

Como refere Fernando Cristóvão: "Foi, sem dúvida, através das viagens de portugueses e espanhóis que chegou aos quatro cantos do Mundo uma visão humanista, técnica, científica e religiosa do melhor que a Europa possuía."²

E levando consigo, ao integrar-se na Comunidade Económica Europeia, as Regiões Autónomas dos Açores e da Madeira, levou também a História que Portugal construiu nestes dois arquipélagos, ou, mais rigorosamente, a História que Portugal construiu, no Mundo, a partir dos Açores e da Madeira.

É bom lembrar, que ainda no último ano, a Diocese do Funchal comemorou os 500 anos da bula do Papa Leão X, "Pro excellenti", de 12 de Junho de 1514, que criou o bispado do Funchal, com jurisdição sobre toda a área ocupada pelos portugueses no Atlântico e no Índico.

Tratou-se assim da primeira Diocese Global, que além da Madeira e do Porto Santo, abrangia Angra, Santiago e S. Tomé, bem como a parte continental de África, o Brasil e Goa, na Índia.

Um arcebispado elevado à categoria de metropolitano e primaz.

Ora, esta História também é parte da História da Europa que integramos.

Mas Portugal, ao aderir à CEE, levou, também, por inevitável ordem natural das coisas, a sua Geografia, incluindo as Regiões Autónomas dos Açores e da Madeira, e, por essa via, alargou as fronteiras da Europa, a Ocidente, até ao meio do Atlântico.

Com as nossas Regiões Autónomas a Europa não acaba, a Ocidente, na ponta de Sagres, no Cabo da Roca ou no Cabo Finisterra, mas bem mais longe, nas Ilhas Selvagens e no ponto mais a Oeste da Ilha das Flores.

Não estou a referir-me a um mero acréscimo de extensão ou área, incluindo toda a sua vasta zona marítima.

\footnotetext{
${ }^{2}$ CRISTOVÃO, Fernando - As viagens e os viajantes para os portos da lusofonia. In RES-PÚBLICA. Revista Lusófona de ciência política e relações internacionais, Lisboa, a.1n.3-4 (2005), p.15-26
} 
Estou a falar do especial valor estratégico, não apenas para Portugal, mas para a Europa.

Aliás, como se tem constatado em várias ocasiões, estes verdadeiros portaaviões do Atlântico são essenciais à segurança do Ocidente.

Como devo lembrar o enorme potencial que as novas e crescentes vertentes da economia do Mar trarão, nas próximas décadas, por via das nossas regiões insulares, tanto para Portugal como para a Europa.

Todavia, a visão dominante, pelo menos mediaticamente, é exactamente a contrária.

Nessa óptica, a União Europeia será tudo (ou, pelo menos, muito) para Portugal, como será tudo para as Regiões Ultraperiféricas dos Açores e da Madeira.

Trata-se de visão simplista e superficial de que as regiões insulares serão um verdadeiro fardo para o País, como o serão para a União Europeia.

Penso, aliás, que o País, as suas elites e os seus media, são responsáveis pela desvalorização que a Europa faz das nossas Regiões Autónomas, pois, tal mais não é do que o reflexo da desvalorização e da ideia de fardo financeiro que se deixou instalar internamente de forma injusta, em relação a territórios que se persiste, ao fim e ao cabo, em tratar como ilhas adjacentes.

Álvaro Monjardino, em comunicação que apresentou no IV Colóquio Internacional das Ilhas do Atlântico, que teve lugar em Tenerife, em Outubro de 1995, já chamava a atenção para esta circunstância.

Referia, então o seguinte: "O Atlântico, na visão - ou na sensibilidade - da União Europeia, não parece destinado a um papel de relevo.”

E acrescentava: "Tudo isto pode explicar-se por antecedentes que vão à raiz da História dos Arquipélagos. Povoados e utilizados na embalagem e no contexto da expansão peninsular, e logo europeia, através do Atlântico, é manifesta a desvalorização que as Ilhas sentem e tem reduzido as mais afortunadas em clima ameno a lugares fundamentalmente de lazer."

E concluía mesmo: "A noção de insignificância instrumental relativamente ao Mundo presente sente-se, com especial embora diferente acuidade, nos Arquipélagos Atlânticos. Afora o mercado do lazer, que pretenderá deles a Europa? Até nem os trata mal, mas como reformados, à falta de uma nova proeminência oceânica que tarda em 
aparecer. E que, se um dia vier, não é provavelmente desta União Europeia que há-de vir."3

A verdade é que o Mundo mudou muito nas últimas décadas e penso que o quadro referido pelo Dr. Álvaro Monjardino já não corresponde às opções europeias de hoje.

Em todo o caso, Alberto Vieira lembra: "O posicionamento periférico da Madeira nunca fez com que a Ilha se afastasse do vínculo europeu. No período áureo dos Descobrimentos, os principais laços estavam na Europa e, só a partir do século XVII, os ingleses a transformaram numa ponte entre a Europa e o mundo colonial."

Ao preparar esta intervenção, lembrei-me, de repente, que, em tempos idos, ao ler o "Corsário das Ilhas", de Vitorino Nemésio, tinha fixado um dado passo, em que aquele ilustre escritor insular descrevia, o que, de certo modo, se poderia considerar a caracterização dos traços mais salientes e intemporais do "madeirense".

Depois de aludir à complexa orografia da Madeira e às suas consequências na fixação demográfica, referia Nemésio: “É nesta dispersão multiplicada, em que o espaço parece que não conta, que uma das populações mais prolíficas e laboriosas de Portugal vive e luta".

E concluía: "O madeirense, aliás, nunca perdeu o seu velho sentido prático endereçado às empresas duradoiras “

O futuro, para ser consistente, não pode deixar de juntar as raízes, e o passado, ao presente.

É também Alberto Vieira que refere algures o seguinte - depois de ter constituído uma força centrífuga relativamente aos povoadores, a Madeira passou a ser objecto de uma força centrípeta, ou seja, polo de irradiação de fluxos migratórios vários, ao longo dos séculos.

Primeiro para destinos mais próximos e, depois, para paragens mais longínquas, dir-se-á mesmo que para as cinco partidas do Mundo.

Os madeirenses passaram, desde logo, a participar na gesta dos Descobrimentos e na colonização dos territórios que foram sendo descobertos e em que Portugal se envolveu nos Séculos XV e seguintes.

A posição geográfica da Madeira tornou-a um ponto de apoio importante na consolidação das Praças que Portugal ocupava, à época, no Norte de África.

\footnotetext{
${ }^{3}$ In "História das Ilhas Atlânticas", Vol. I, Região Autónoma da Madeira, fls. 233 e seguintes.

${ }^{4}$ In "História da Madeira", fls 378.
} 
Em 1510 Simão Gonçalves da Câmara, Capitão donatário do Funchal escreveu ao Rei, referindo que, até Maio desse ano teria disponíveis 102 homens para partirem para Safim.

Não deixou, porém, de lembrar que "os madeirenses que já anteriormente tinham ido a Safim pediam que o Rei lhes pagasse o mantimento que estava em atraso.". 5

A História parece que se repete, pois, também hoje existem pendências e atrasos semelhantes entre a Região e a República.

Foi, pois, nesta síntese de projecção no Mundo, neste constante sentido de partir, por um lado, mas sem abandonar as raízes europeias, que as populações das Regiões Autónomas construíram a sua História, parte importante da nossa História.

E é também uma mais valia de Portugal, e da Europa, as suas comunidades espalhadas pelo Mundo, hoje com particular destaque e relevância nas sociedades de destino em que se inseriram - os Açorianos em especial nos Estado Unidos e no Canadá e os Madeirenses, de forma particular, na Venezuela e na África do Sul.

A Europa actual, como o indicia o Tratado de Livre Comércio, em negociação entre a União Europeia e os Estados Unidos da América do Norte, está mais atenta e dá maior relevo à vertente Atlântica.

A questão, na minha opinião, e no que respeita a uma menor atenção ao valor acrescentado que as Regiões Autónomas portuguesas trazem à União Europeia, deve-se à circunstância de não haver, no domínio da defesa, uma política com o sentido e alcance das demais políticas comuns europeias.

Nem mesmo por via de Organizações como a UEO e a OSCE se logrou atingir um sentido de defesa comum, integrado ou plenamente associável, à União Europeia.

Penso que a circunstância da defesa e da segurança da Europa, em especial na sua vertente militar, estar, ao fim e ao cabo, confiada à NATO, sob a liderança dos Estados Unidos, tem levado, pelo menos aparentemente, a que se subalternize a efectiva e real importância estratégica dos nossos Arquipélagos do Atlântico, no âmbito Europeu.

É que este triângulo estratégico (fronteira externa da União Europeia), constituído pelo Continente e as duas Regiões Autónomas, como é reconhecido pelo actual "Conceito Estratégico de Defesa Nacional", é essencial à defesa da Europa e do Ocidente em geral.

\footnotetext{
${ }^{5}$ SOUSA, João José de - 'Emigração Madeirense nos Séculos XV a XVII'. In Revista Atlântico, no 1 , 1985, fls 46 e seguintes.
} 
Assim, não deve ser a circunstância da defesa da Europa, no fundamental, se desenvolver sob o chapéu-de-chuva da NATO e dos Estados Unidos, que deve levar a que a União Europeia não tenha em consideração a relevância e a mais valia de Portugal na Europa por via das suas Regiões Autónomas Insulares e Atlânticas.

Basta, aliás, ter presente o papel histórico da base das Lages. Nos Açores (agora em redução numérica da presença militar americana), mas sem pôr em causa a sua utilização e operacionalidade.

Como não deixa de ser curioso que o primeiro aeroporto construído na Região Autónoma da Madeira não tenha sido desde logo na Ilha principal do Arquipélago, mas no Porto-Santo.

A explicação é fácil e deveu-se a prioridade estratégica por parte do Atlântico em função da cobertura dos acessos aos Estreito de Gibraltar.

A Madeira só veio a ter aeroporto muito mais tarde.

A outra vertente, da maior actualidade, e a que já fiz referência, nesta visão que falta à União Europeia, da importância das nossas regiões insulares, tem a ver com as potencialidades que a economia do Mar vai proporcionar nas próximas décadas.

Portugal com a extensão do seu Mar Territorial, Zona Contígua, Zona Económica Exclusiva e da Plataforma Continental, que a Convenção do Mar, das Nações Unidas lhe reconhece, com grande probabilidade de vir a ser ampliada, consideravelmente, com a resolução da questão pendente relativa às Ilhas Selvagens, conferirá ao nosso País a mais vasta extensão de águas territoriais de praticamente toda a Europa.

Não deixa de ser curioso que, em 2002, mapas da União Europeia, colocados no seu site, incluíssem as Ilhas Selvagens, na Comunidade Autónoma de Canárias, o que deu lugar a uma carta de protesto dirigida pelo Deputado europeu, Sérgio Marques, ao então Presidente da Comissão, Romano Prodi, exigindo a correcção de tão grosseiro erro. ${ }^{6}$

A propósito das potencialidades do Mar para a economia portuguesa (e por isso também europeia) no futuro próximo refere Rui Martins o seguinte: "O Mar tem que ser o eixo fundamental do desenvolvimento de Portugal nas próximas décadas. Deve servir de plataforma para reforçar os laços com os Países Lusófonos, recuperando assim uma

\footnotetext{
${ }^{6}$ JOSÉ, Pedro Quartin Graça Simão - A Importância das Ilhas no Quadro das Políticas e do Direito do Mar, o Caso das Selvagens (A disputa da Última Fronteira). Lisboa: Chiado Editora, 2014. ISBN 978989-51-2324-7.
} 
aproximação que a adesão europeia quis esquecer. Há que elaborar uma política abrangente e extensa para o Mar, que inclua estímulos fiscais, políticas de investigação universitária, com "ninhos de empresa" e investimentos públicos descomplexados. Tornado em desígnio estratégico principal, o Mar há-de cumprir o papel que a Índia, o Brasil e África cumpriram em eras passadas da História de Portugal, mas sem o estéril fito do lucro imediato ou especulativo, nem a imoralidade da escravatura e da colonização que caracterizaram esses três Impérios passados. Bem pelo contrário, esse "quarto Império", há-de ser o da produção (bem menos que o comércio), da Ciência e da Investigação e, decorrentemente, do Homem e do seu poder criativo."7

Tivemos anos de costas voltadas para a Europa e ao aderirmos à CEE voltámos costas ao Mar.

Não é forçoso, nem devemos admitir, como fatalidade, que as duas coisas não sejam conciliáveis.

É certo que, em muitos casos, as políticas comunitárias colidem com opções nacionais, mas cabe-nos exigir a necessária compreensão europeia para o nosso próprio condicionamento geográfico e para a mais valia que tal representa para a Europa.

Não tem sentido, com o Mar que temos, que $60 \%$ do pescado que consumimos seja importado e grande parte dele seja pescado nas nossas águas pela frota pesqueira espanhola.

Algo está errado em situações como esta!

Tiago Pitta e Cunha lembra, e bem, o seguinte: "O que está errado é que a ideia de Europa nos tenha deslumbrado tão profundamente, ao ponto de acharmos que nos podíamos dar ao luxo de dispensar a nossa geografia, e de nos abstermos de explorar o nosso recurso principal - o mar - esquecendo-nos do que somos e de onde vimos. O que é pena é que não tenhamos percebido que era (...) nessa nossa ligação ao mar (e através dele com o resto do Mundo) que estava o conteúdo mais valioso do nosso contributo para o projecto europeu.",

As Universidades de ambas as Regiões Autónomas, e muito em especial a Universidade dos Açores, têm dado prioridade, e estão dotadas de centros de excelência no domínio da biologia marítima, sem que, no entanto, se tenha sabido, até hoje, aproveitar devidamente esses importantes contributos científicos.

O Mar como é sabido faz parte da nossa identidade.

\footnotetext{
${ }^{7}$ MARTINS, Rui - “O Mar como Desígnio Nacional”, fls. 23 e seguintes.

${ }^{8}$ CUNHA, Tiago Pitta e - Portugal e o Mar. Lisboa: Fundação Francisco Manuel dos Santos, 2011, p. 12.
} 
Não admira, pois, que a nossa literatura seja rica a propósito do Mar e frequentemente nele inspirada.

Não resisto, pois, a terminar, lembrar Virgílio Ferreira, no seguinte trecho: “A alma do meu País teve o tamanho do Mundo (...) uma língua é o lugar de onde se vê o Mundo, e em que se tratam os limites do nosso pensar e sentir. Da minha língua vê-se o Mar. Na minha língua ouve-se o seu rumor, como das dos outros se ouvirá o da floresta ou o silêncio do deserto. Por isso a voz do Mar foi em nós a da nossa inquietação. Assim o apelo que vinha dele foi o apelo que ia de nós.",9

E o português, que navegou por todos os mares do Mundo, mesmo os mais agitados e encrespados, e também é língua oficial da União Europeia, tem de se saber fazer ouvir nas instâncias europeias!

\footnotetext{
9 “A Voz do Mar”, 1991, citado por Joaquim Miguel Patrício. In "Não culpem nem Sacralizem o Mar”, 2011, p.35.
} 